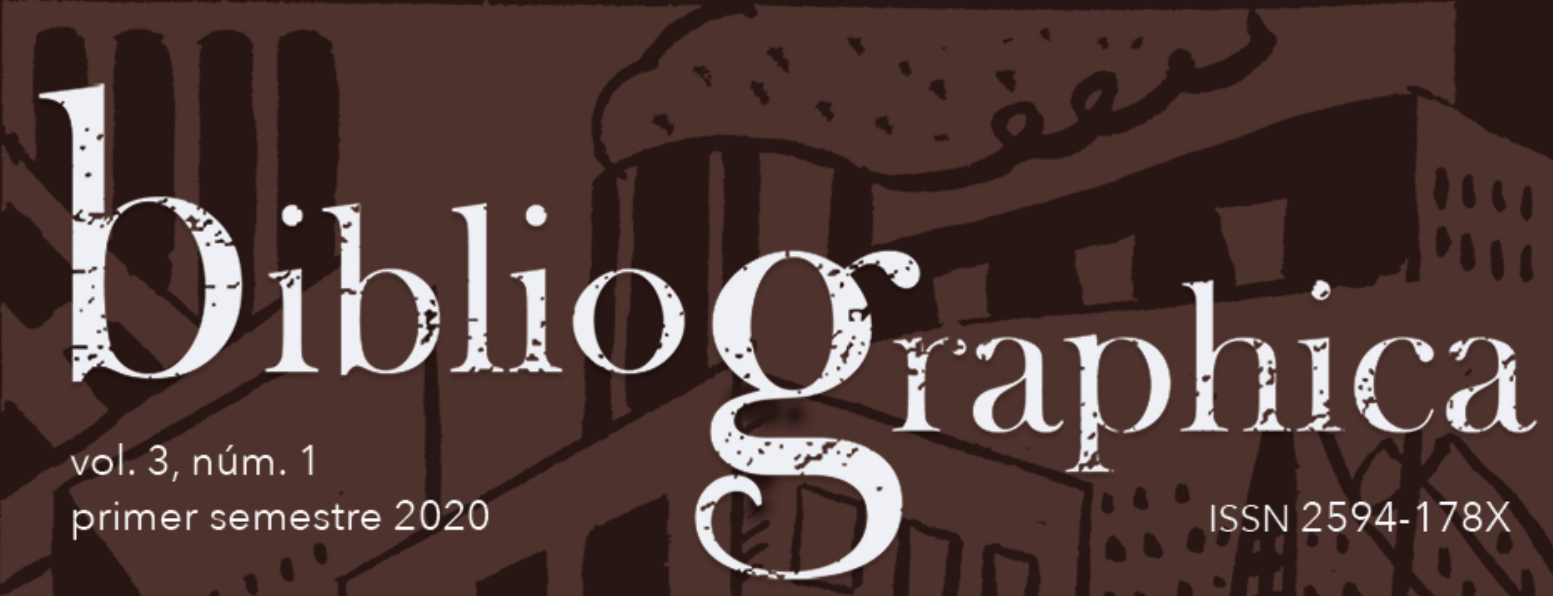




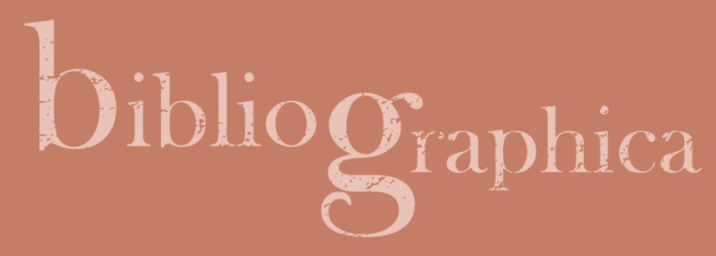

\section{Los precursores (estéticos) de los Breviarios del Fondo de Gultura Económica}

The (Aesthetic) Precursors of the Fondo de Cultura Económica's Breviarios Collection

\section{Nora G. Benedict}

nbenedict@uga.edu

Universidad de Georgia

Departamento de Lenguas Romances

Recepción: 02.10.2019 / Aceptación: 09.01.2020

DOI: https://doi.org/10.22201/iib.2594178xe.2020.1.62 
Resumen La colección Breviarios es una de las más notables y exitosas del Fondo de Cultura Económica. Transformó completamente la industria editorial latinoamericana debido a la calidad física e intelectual de cada tomo presentado a sus lectores. Para entender mejor el impacto y las raíces estético-educativas de la colección en sí, examinaré una serie de sus precursores globales. En particular, analizaré varias colecciones mundiales de la primera mitad del siglo XX, desde las de Albatross Press y Penguin Books hasta las de Emecé Editores, por su formato y contenido. Además, compararé y contrastaré las estrategias editoriales y artísticas de esos precursores, para subrayar el carácter novedoso de los Breviarios.

Palabras Historia del libro; Fondo de Cultura Económica; industria editorial global; diseclave ño del libro; colección de libros.

Abstract The Breviarios is one of the Fondo de Cultura Económica's [Economic Culture Fund] most prominent and successful collections. Without a doubt, the physical and intellectual quality of each volume in the series completely transformed the publishing industry in Latin America. In order to better understand the impact and origins -both aesthetic and educational- of the collection itself, I will examine a series of its global precursors. In particular, I will analyze various international collections since the first half of the $20^{\text {th }}$ Century, from those of Albatross Press and Penguin Books to those of Emecé Editores, for their form and content. In addition, I will compare and contrast the artistic and publishing strategies of those forerunners in an effort to stress the originality of the Breviarios.

Keywords Book history; Fondo de Cultura Económica; global publishing industry; book design; book collection. 
The True University of These Days

is a Collection of Books.

Thomas Carlyle

"The Hero as Man of Letters" (1840).

\section{Introducción}

Como han señalado muchos críticos, la colección Breviarios es una de las más notables y exitosas del Fondo de Cultura Económica (FCE). Sin lugar a dudas, transformó por completo la industria editorial latinoamericana gracias a la calidad física e intelectual de cada libro editado. Con el propósito de crear una biblioteca universal y completa al alcance de cualquier lector de América Latina, esta serie redefinió qué significa la idea del acceso en la industria editorial mexicana del siglo XX. Dicho eso, para una mejor comprensión del impacto y las raíces -tanto estéticas como educativas- de la colección en sí, examinaré una serie de sus precursores globales. Particularmente analizaré varias colecciones internacionales de la primera mitad del siglo, desde las de Albatross Press y Penguin Books hasta las de Emecé Editores, por su formato y contenido. Además, compararé y contrastaré las estrategias editoriales y artísticas de esos precursores para hacer hincapié en lo novedoso de los Breviarios no sólo en América Latina, sino también en el mundo entero. Para facilitar el desarrollo de mis argumentos, dividí este estudio en tres partes: la primera está dedicada a la historia y creación de los Breviarios, la segunda se enfoca en el formato de los libros en esta colección y algunos de sus precursores globales, mientras que la tercera examina las coincidencias en el contenido de los Breviarios y sus precursores.

En términos generales, este estudio se inscribe en el área de la historia del libro, o el análisis de los aspectos físicos del libro como objeto en sí. Puesto que este campo de estudio abarca diversas teorías y perspectivas analíticas, quiero precisar mi metodología con más detalle. Como punto de partida, utilizo los estudios de Donald F. McKenzie y G. Thomas Tanselle sobre la importancia de los aspectos estéticos del libro. 'Según McKenzie, "to reconstruct our literary past,

\footnotetext{
${ }^{1}$ Véanse Donald Francis McKenzie, Bibliography and the Sociology of Texts (Cambridge, MA: Cambridge University Press, 1999) y Making Meaning: "Printers of the Mind" and Other Essays, ed. de Peter D. McDonald y Michael F. Suarez (Amherst, MA: University of Massachusetts Press, 2002); G. Thomas Tanselle, Bibliographical Analysis. A Historical Introduction (Cambridge, MA: Cambridge University Press, 2009) y Literature and Artifacts (Charlottesville, VA: Bibliographical Society of the University of Virginia, 1998).
} 
we cannot be indifferent to the details of book form, in the contribution design makes to meaning, in mediating authorial intention and directing the responses of readers". Por tanto, los elementos visuales del libro tales como la tipografía, la organización de las portadas y el uso de imágenes serían centrales para mi análisis. Más específicamente, examinaré "the intended role of design in particular verbal works, as well as the effect of such designs (whether the intended effect of not) on readers". ${ }^{3}$ Dado que la estética de cualquier libro depende de su contenido, también consideraré la tendencia de los Breviarios de reciclar obras publicadas por otras editoriales $y$, a la vez, dividir los libros en categorías temáticas, de manera parecida a sus precursores.

Antes de entrar en un análisis sobre la producción material del FCE, hay que describir brevemente cómo era la industria del libro en América Latina en ese momento - desde la producción y diseño de los libros hasta su distribución y venta en librerías-. Por lo general, el número de editoriales, imprentas, talleres de encuadernación y librerías en América Latina creció exponencialmente durante la primera mitad del siglo XX. Con la erupción de la Guerra Civil española en 1936, se notó un aumento bastante grande de exiliados españoles en ciertos países de América Latina, en búsqueda de trabajos y una nueva vida durante ese periodo. La centralidad de España en la industria del libro a lo largo de ese siglo justifica la facilidad con la que la mayor parte de estos exiliados entraron al mundo editorial en América Latina. En particular, se suele destacar la importancia de Cuba, México y Argentina dentro del mundo editorial durante esta etapa, por su dominio del mercado. ${ }^{4}$ Respecto a la situación específica de la industria editorial en México durante el siglo XX, había un gran desarrollo del libro masivo, justo después de la Revolución mexicana. En concreto, hay que subrayar las iniciativas radicales del primer titular de la Secretaría de Educación Pública (SEP), José Vasconcelos, quien produjo y distribuyó (gratuitamente) cantidades

\footnotetext{
${ }^{2}$ McKenzie, "Typography and Meaning: The Case of William Congreve", en Making Meaning: "Printers of the Mind" and Other Essays, 233.

${ }^{3}$ Tanselle, Bibliographical Analysis, 81.

${ }^{4}$ Véanse Jorge B. Rivera, La forja del escritor profesional (1900-1930). Los escritores y los nuevos medios masivos (Buenos Aires: Centro Editor de América Latina, 1967) y "El auge de la industria cultural (1930-1955)", en El escritor y la industria cultural (Buenos Aires: Centro Editor de América Latina, 1981), 94-127; José Luis de Diego, "Actualidad del mercado del libro. El caso argentino", Revista Hispánica Moderna 71.2 (2018): 131-150; Tomás Granados Salinas, Libros (México: Secretaría de Cultura, 2017); Jacqueline Laguardia Martínez, "La industria editorial cubana: evolución y desarrollo", en Memorias 22. Feria Internacional del Libro de La Habana (La Habana: Editorial Científico-Técnica, 2012), 160-197.
} 
enormes de libros para la población mexicana. ${ }^{5}$ Como veremos a continuación, la creación de los Breviarios se inspiró en estos enfoques de Vasconcelos, en los tirajes masivos y la educación general de un público más amplio.

\section{El Fondo de Cultura Económica y los Breviarios}

A principio de los años 30, Daniel Cosío Villegas notó la escasez de obras técnicas y bien hechas para los estudiantes de la Escuela Nacional de Economía en México. Él y varios otros profesores de economía deseaban producir unos títulos -algunos en traducción- que aumentaran los catálogos nacionales y las estanterías estudiantiles. Con un plan bien desarrollado y una propuesta sólida para producir 50 libros, Cosío Villegas se dirigió a la casa editorial Espasa-Calpe en España para publicar los textos académicos en cuestión, pero José Ortega y Gasset lo rechazó de manera muy ofensiva. ${ }^{6}$ Después de su fracaso inesperado en Madrid, Cosío Villegas regresó a México con ganas de "crear una casa editora, sin fines de lucro, que atendiera las necesidades de la joven Escuela Nacional de Economía", sin la ayuda de cualquier empresa española. ${ }^{7}$ Esta idea lo llevó a fundar el Fondo de Cultura Económica en 1934, con Emigdio Martínez Adame, Eduardo Villaseñor y Gonzalo Robles. Desde sus inicios se asocia esta editorial con la vida académica e intelectual no sólo de México, sino también de América Latina, en términos generales. Más aún, esta casa editora hizo hincapié en la importancia del acceso a "un rico material bibliográfico que permanecía inalcanzado u oculto, en ediciones agotadas o de idiomas ajenos". ${ }^{\prime}$ Por tanto, desde sus orígenes el FCE tenía una reputación por su promoción del acceso al libro en español, tanto sobre temas españoles/latinoamericanos como temas de interés global.

\footnotetext{
${ }^{5}$ Véanse Francisco Javier Rosales Morales, "Un acercamiento a los lectores de las publicaciones de la Secretaría de Educación Pública", Revista Mexicana de Historia de la Educación 4.8 (2016): 175-199 y Claude Fell, José Vasconcelos: los años del águila (19201925). Educación, cultura e iberoamericanismo en el México posrevolucionario (México: Universidad Nacional Autónoma de México, 1989).

${ }^{6}$ Daniel Cosío Villegas recuerda que Ortega y Gasset respondió a su propuesta con las siguientes palabras: "El día en que los latinoamericanos tuvieran que ver algo en la actividad editorial de España, la cultura de España y la de todos los países de habla española 'se volvería una cena de negros'", Memorias (México: Conafe, 1986), 146.

${ }^{7}$ Granados Salinas, Libros, 175.

${ }^{8}$ Arnaldo Orfila Reynal, "Orígenes y misión de 'Fondo de Cultura Económica'", Gaceta del Libro 3 (1945): 26. Para más detalles sobre la fundación del FCE, véanse Díaz Arciniega, Garciadiego, Krauze y Sorá.
} 
Dado los intereses del FCE por aumentar la disponibilidad y el acceso a libros de calidad en español en América Latina, fue lógico que se abriera su primera sucursal en 1944 en Buenos Aires, otro epicentro editorial latinoamericano del siglo XX. La elección de Buenos Aires para su primera filial también refleja la predilección mexicana por los libros argentinos, lo cual se manifiesta en la estadística de 1945: "70 por ciento de los libros que vendían en [México] eran editados en la Argentina". 9 Dicho de otra manera, fue un interés compartido y mutuamente beneficioso para ambos países. En términos generales, el gran propósito de esta filial argentina fue la distribución y promoción de la producción editorial del FCE en otras partes de América Latina.

A sabiendas de que no podría dirigir la casa editorial central y la filial argentina a la vez, Cosío Villegas nombró a Arnaldo Orfila Reynal, amigo suyo de la juventud, director de esta sucursal, una decisión que influyó mucho en la dirección y visión del FCE. Se nota la influencia de una perspectiva nueva y más amplia en un artículo de la Gaceta del Libro (1945), donde Orfila Reynal anunció que la "función [de la filial argentina] será la de agrandar y extender los caminos de su difusión, acercando la obra del pensamiento de aquel gran pueblo al lector, al escritor y al librero de nuestros países, que lo acogen con fervorosa simpatía".10 Este nuevo director dijo incluso que "esa gran empresa cultural [...] quiere llegar a todos los ámbitos de América" con sus libros y, por consiguiente, el rol de la sucursal argentina sería de suma importancia para la editorial mexicana. ${ }^{11}$

Cuatro años más tarde, en 1948, Cosío Villegas quería enfocarse en sus propias investigaciones académicas y cedió su rol de director del FCE a Orfila Reynal, quien mantendría este puesto durante 17 años. Aunque Cosío Villegas dejó huella en esta casa editorial debido a la cantidad y la calidad de los libros que publicó a lo largo de sus 14 años como director, los años posteriores con Orfila Reynal fueron "los más brillantes del Fondo por la orientación intelectual y por la diversidad de su programa de publicaciones, que incluyó colecciones de divulgación literarias".12 Además de ser el responsable de la publicación de casi 900 títulos, Orfila Reynal también reinició la publicación del Noticiero Bibliográfico en su segunda época, fundó La Gaceta y abrió la primera librería de la casa

\footnotetext{
9 Alberto M. Candioti, "Hay gran demanda de libros argentinos en México", Gaceta del Libro 3 (1945): 27-28.

10 Orfila Reynal, "Orígenes y misión....", 26.

$11 \mathrm{lbid}$.

${ }^{12}$ Granados Salinas, Libros, 182.
} 
editorial en la Ciudad de México durante ese periodo. ${ }^{13}$ En conjunto, todo lo que Orfila Reynal hizo como director del FCE aumentó la visibilidad global de la empresa y, a la vez, ayudó a establecer su estilo distintivo, o su marca, en el mundo editorial.

Si bien toda la producción del FCE durante la época de Orfila Reynal -tanto editorial como promocional- merece una discusión detallada y analítica, en estas páginas solamente me enfoco en una colección suya que apareció por primera vez a mediados del siglo XX: los Breviarios. Según el texto en la sobrecubierta de los libros, "el FCE aspira a formar con ellos la base de una biblioteca que lleve la universidad al hogar, poniendo al alcance del hombre o la mujer no especializados los grandes temas del conocimiento moderno. Redactados por especialistas de crédito universal, cada uno de los Breviarios constituirá un tratado sumario y completo sobre la materia que anuncie su título; en su conjunto, cuidadosamente planeado, formarán esa biblioteca de consulta y orientación que la cultura de nuestro tiempo hace indispensable". ${ }^{14}$

Para lograr esta meta de crear una "biblioteca de consulta" para todos, Orfila Reynal no sólo pensaba en el contenido de los libros y los expertos que los escribirían, sino también en la presentación física de cada libro en sí. Por eso, todos tendrían un formato igual y uniforme que los distingue de cualquier otro libro en el mercado mexicano: unos tomos pequeños $(17 \times 10.5 \mathrm{~cm})$ de tapa dura con una sobrecubierta. Más aún, se agruparon todos los libros en seis categorías temáticas, asociadas con un color distinto: arte (magenta), literatura y estudios literarios (anaranjado), historia (verde claro), religión y filosofía (violeta), psicología y ciencias sociales (azul), ciencia y técnica (amarillo) y economía (verde oscuro). Por ejemplo, el primer libro que se publicó en los Breviarios, la Historia de la literatura griega por C. M. Bowra, lleva una franja anaranjada para marcarlo como un texto sobre la literatura, mientras que los siguientes dos títulos, La Inquisición española por A. S. Turberville y La diplomacia por H. Nicolson, llevan franjas de color verde claro y azul, respectivamente.

${ }^{13}$ El Noticiero Bibliográfico apareció por primera vez en 1939. Orfila Reynal empezó su segunda época en 1940. La Gaceta inicialmente vio la luz en 1948 y todavía sigue apareciendo mensualmente. En general, ambas publicaciones ofrecieron al público más lecturas relacionadas con las obras publicadas por el FCE, como artículos, reseñas o fragmentos de las obras en sí.

${ }^{14}$ Algunas ediciones tardías presentan cambios en este texto de la sobrecubierta, pero la mayor parte del mismo texto y su mensaje quedan sin arreglos. El que reproduzco viene de la sobrecubierta del primer libro dentro de la colección en sí: la Historia de la literatura griega por C. M. Bowra (1948). 


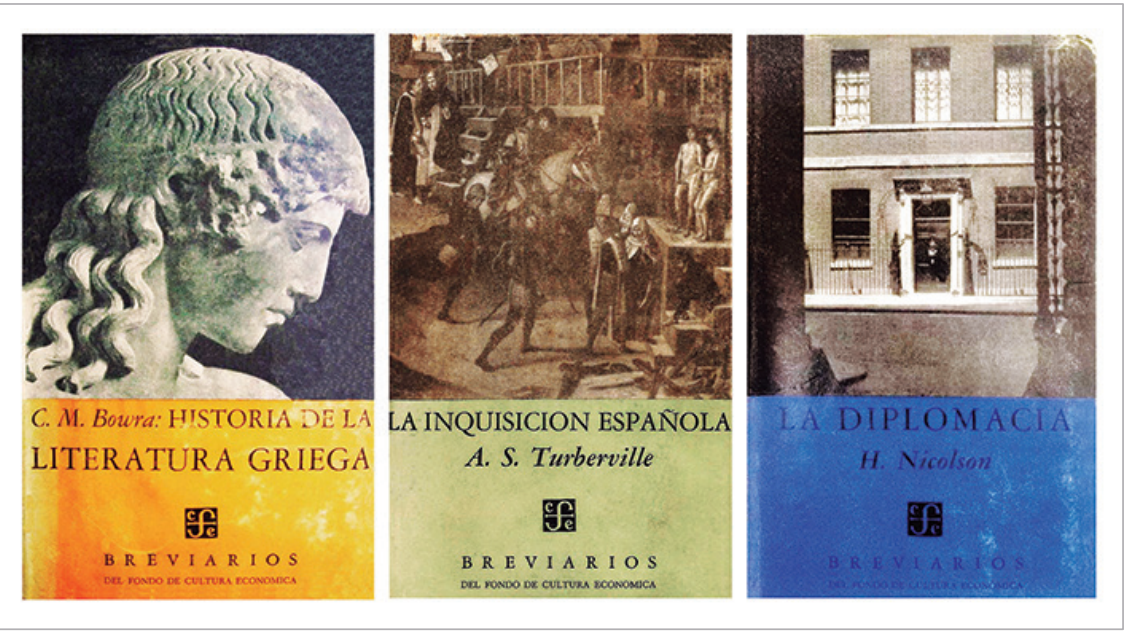

Imagen 1. Portadas de los tres primeros libros en la colección Breviarios (1948).

A pesar de que una de las categorías está dedicada a la economía, lo cual refleja los intereses iniciales de la editorial, la gran mayoría de los títulos se ubica dentro de las otras categorías establecidas. Específicamente, tres de los primeros 10 títulos de la colección en sí, publicados durante 1948 y 1949, caben dentro de la categoría de literatura (30\%), dos son de historia (20\%), dos de arte (20\%), uno es de ciencia/técnica (10\%), uno de psicología/ciencias sociales (10\%) y uno de religión/filosofía (10\%). Así que, desde sus inicios, probablemente gracias a Orfila Reynal, los Breviarios demuestran predilección por las humanidades en vez de las ciencias (o las ciencias sociales). Dicho eso, se notan varios cambios en la distribución temática a lo largo de los años. Por ejemplo en 1951, cuando había alrededor de 50 títulos en la serie, más de $20 \%$ de ellos corresponden a la/s psicología/ciencias sociales (11 títulos), mientras que la categoría de la literatura solamente tenía unos ocho títulos (15\%). En 1957, cuando el número de títulos en la colección llegó a 125, había aún más cambios en las distribuciones temáticas: la mayor parte se relacionaba con la religión/filosofía; tanto la historia como el arte contaron con 23 títulos; y la/s psicología/ciencias sociales solamente tenía unos 20 títulos (16\%). El hecho de que no hubiera una categoría temática que dominara la producción editorial de los Breviarios revela el propósito intelectual de la serie y el buen liderazgo de Orfila Reynal como director de la colección. A continuación veremos que los aspectos 
visuales de los Breviarios serán una clave crucial para entender mejor algunas de las decisiones estéticas que tomó Orfila Reynal con esta colección.

Otra característica llamativa es el gran número de copias producidas en el tiraje y edición de cada título. Por lo general, los tirajes de los libros en esta colección solían ser de entre 5 mil y 10 mil copias, lo cual es enorme en contraste con otras editoriales latinoamericanas o europeas durante el siglo XX. Más aún, cada libro pasó por varias y frecuentes ediciones y (re)impresiones. En algunos casos ciertos títulos pasaron por hasta 17 reimpresiones distintas, cada una con tiradas igualmente grandes, lo cual señala, por un lado, la demanda por los libros de la serie y, por otro, la efectividad de su precio de venta, accesible para el público. ${ }^{15}$ En cuanto al precio específico de los libros, cada tomo pertenecía a una de dos categorías, que correspondían al tamaño del libro en sí: volumen sencillo o volumen extra. En concreto, se refiere al número de páginas que contenían: los volúmenes sencillos no solían tener más de 220 páginas y costaban unos 5 pesos, mientras que los extras tenían más de 220 páginas y su precio era de unos 9 pesos. ${ }^{16}$

\section{El formato: una estética compartida}

Sin duda, gran parte del éxito de los Breviarios fue su formato. Dado que la colección todavía existe y los títulos siguen llenando las páginas de los catálogos del FCE, pueden notarse algunos cambios estéticos a lo largo de los años. De hecho, Marina Garone Gravier divide la producción editorial de esta colección en cuatro etapas distintas. En la primera etapa (1948-1965) se nota el uso del "fotograbado, generalmente en blanco y negro" para las portadas e imágenes, que en sí tienden a "aludir al tema en cuestión, aunque no siempre es fácil localizar el mejor ejemplo visual".17 La segunda etapa (1965-1975) mantiene una organización visual similar a la de la primera, pero las imágenes que aparecen

\footnotetext{
${ }^{15}$ Por ejemplo el título de Werner Wolff, Introducción a la psicología. Este libro solamente pasó por ocho reimpresiones dentro de mi periodo de estudio (1945-1965), pero llegó a la decimoséptima reimpresión en 1978.

${ }^{16}$ Estos precios corresponden a mi periodo de enfoque (1948-1965). El precio de estos volúmenes en otros países difirió por la tasa de cambio. Por ejemplo, en Estados Unidos un volumen sencillo de los Breviarios costaba unos 75 centavos de dólar, mientras que un volumen extra valía 1.40 .

${ }^{17}$ Marina Garone Gravier, Historia en cubierta: El Fondo de Cultura Económica a través de sus portadas (1934-2009) (México: FCE, 2011), 115.
} 
en las portadas "fueron realizadas ex profeso para los libros". ${ }^{18}$ La tercera etapa (1975-2002) sigue con muchos elementos de diseño de la segunda, aunque se distingue de la etapa previa por su "uso intensivo de fotografías a color o alteradas con procedimientos de fotomecánicas". ${ }^{19}$ Finalmente, la cuarta etapa (2002 al presente) se caracteriza por los esfuerzos de Pablo Rulfo en rediseñar la serie y repensar algunos aspectos alrededor de la organización horizontal del espacio de cada portada. Además, se nota un regreso a "una paleta cromática para identificar los géneros" o los temas de la serie. ${ }^{20}$ Dicho todo eso, aquí solamente me enfoco en la producción de los Breviarios bajo la dirección de Orfila Reynal, lo cual constituyó "una gestión que marcó de manera profunda el rumbo editorial del Fondo y, por extensión, de sus portadas", y se limita a los años de 1948 a 1965, o sea la primera etapa de la colección. ${ }^{21}$

En términos generales, como ya mencioné, cada libro que forma parte de los Breviarios durante esos años se distingue por ser del mismo tamaño (17 x $10.5 \mathrm{~cm}$ ) y por llevar una sobrecubierta única. En cuanto a las sobrecubiertas, suelen tener una imagen o foto en la portada, junto con información bibliográfica, como el nombre del autor y el título de la obra, que se presenta dentro de un rectángulo en un color vinculado con una de las categorías temáticas de la colección. ${ }^{22}$ Por ejemplo, el primer libro de la serie entera cae dentro de la categoría temática de la literatura, lo cual se distingue estéticamente por el uso del color anaranjado en su franja.

En la contraportada de cada sobrecubierta normalmente está una descripción de la colección de los Breviarios y su misión, junto con una lista de las categorías temáticas de la serie. Además de la información en estas dos secciones principales de la sobrecubierta, hay detalles cruciales en cada una de las solapas. La solapa conectada con la portada de la sobrecubierta tiene un resumen de la obra en cuestión y una explicación breve de las credenciales del experto, o expertos, que la escribió. La solapa del fondo tiene información sobre otros títulos publicados, además de algunos detalles sobre los de próxima aparición.

\footnotetext{
${ }_{18} \mathrm{lbid}$

${ }^{19} \mathrm{lbid}$.

${ }^{20} \mathrm{lbid}$.

${ }^{21}$ lbid.; énfasis mío.

22 En cuanto al uso de imágenes en las portadas, es importante señalar que cada nueva edición (o reimpresión) presenta una ilustración o foto diferente al lector, lo cual hace más fácil distinguir una edición de otra.
} 


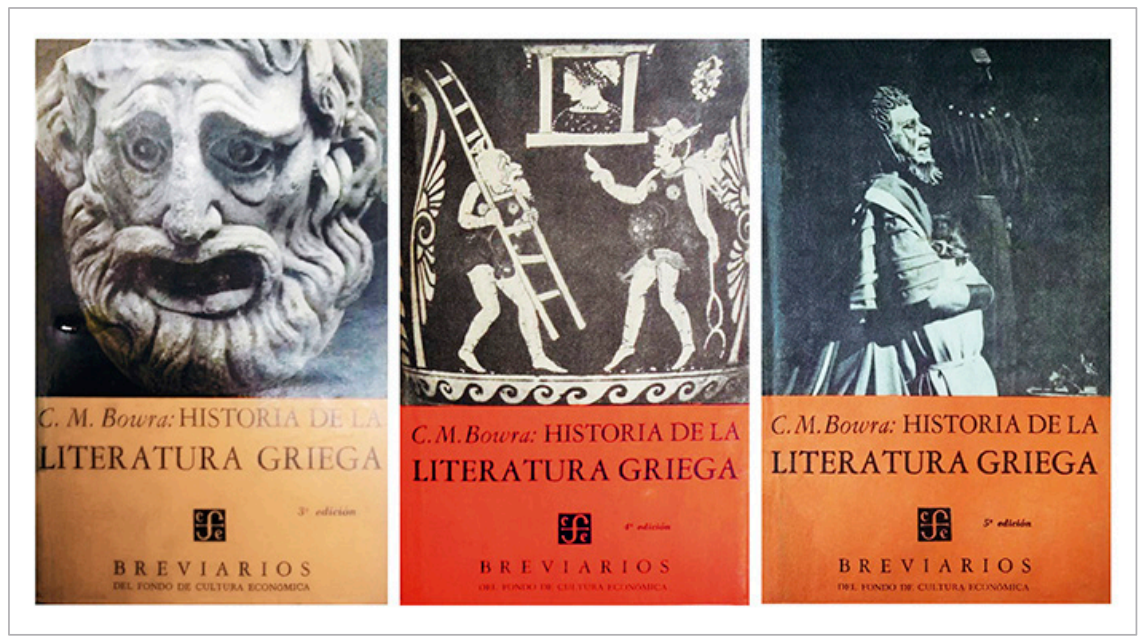

Imagen 2. Algunos ejemplares del primer libro de los Breviarios (3a., 4a. y 5a. ediciones).

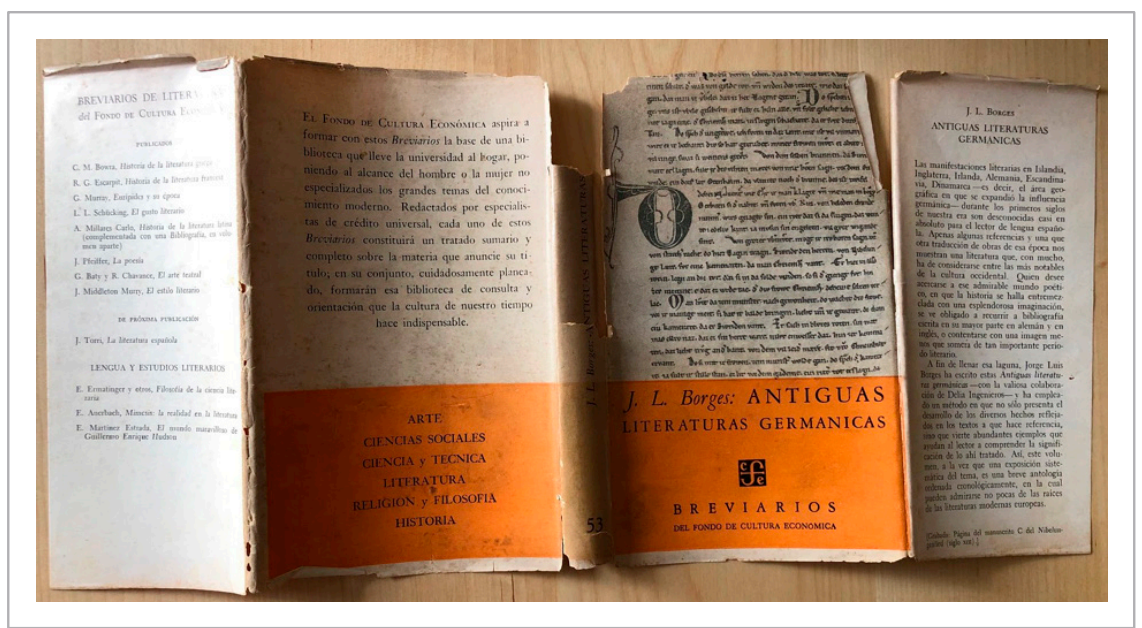

Imagen 3. Sobrecubierta de Antiguas literaturas germánicas (1951), escrito por Jorge Luis Borges con la colaboración de Delia Ingenieros. 


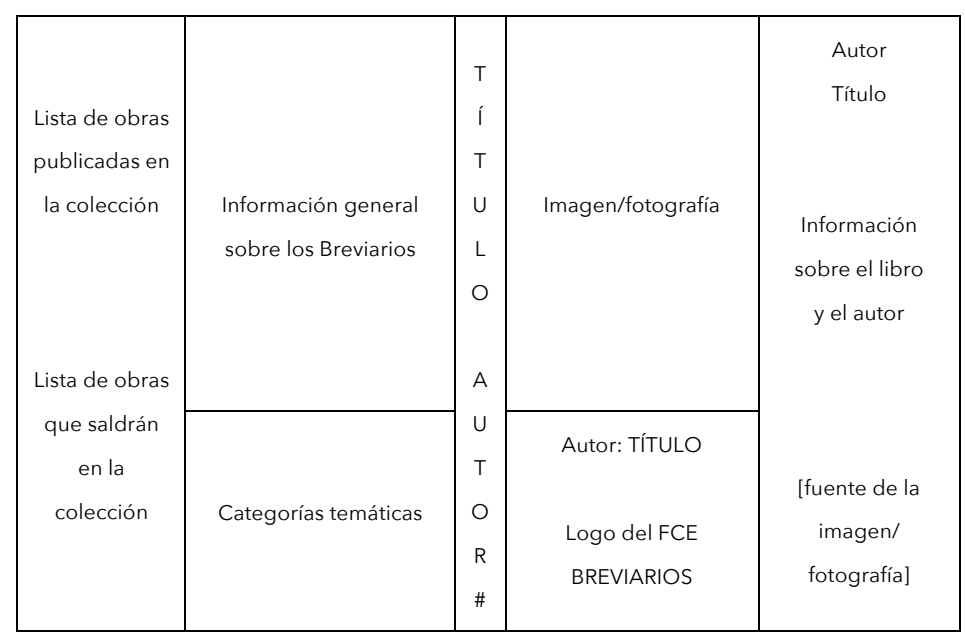

Imagen 4. Esquema general de la información básica presente en las sobrecubiertas de los Breviarios.

Si bien estos detalles materiales ayudan a cualquier persona a diferenciar un tomo de la serie del FCE de cualquier otro libro producido en América Latina, hay que subrayar los precursores estéticos de estos diseños. La tendencia del FCE de agrupar los libros producidos en varias colecciones, o aun bibliotecas como los Breviarios, no fue algo totalmente nuevo en ese momento. De hecho, varias casas editoriales ya habían empezado a hacerlo desde principios del siglo XX. Por tanto, es importante describir los libros de algunas series literarias e históricas de otras editoriales globales que poseen aspectos físicos similares a los Breviarios, con el fin de señalar las deudas artísticas que el FCE debe a otras firmas internacionales. Ciertos críticos ya han señalado los paralelos estéticos entre los Breviarios y algunas colecciones literarias globales como los libros icónicos de Penguin Books. ${ }^{23}$ Sin embargo, hay que identificar

${ }^{23}$ Ver Víctor Erwin Nova Ramírez, "Arnaldo Orfila Reynal. El editor que marcó los cánones de la edición latinoamericana" (tesis de maestría, UAM, 2013). Este autor también alude al vínculo entre los Breviarios y los Penguin Books: "La propuesta de crear una biblioteca popular, económica en su versión de bolsillo no representaba una novedad. Su antecedente se remonta a los legendarios Peng[u]in Books (1935) en Inglaterra. Este sello editorial se propuso publicar a precios económicos y, a través, de un sistema de distribución alternativo a las librerías, colocando sus libros en estantes dentro de tiendas comerciales y estaciones ferroviarias", "Arnaldo Orfila Reynal...", 135-136. 
todos los precursores de diseño posibles y destacar las semejanzas entre ellos sistemáticamente, para llegar a una comprensión más detallada de los orígenes de esta serie latinoamericana. En términos específicos, a continuación analizaré el diseño y presentación de los libros de Albatross Press, Penguin Books y la Biblioteca Emecé de Obras Universales, que tienen mucho en común con las ediciones de los Breviarios. ${ }^{24}$ Puesto que me interesa la cuestión de cuáles son algunos de sus precursores estéticos, examinaré cada una de estas colecciones en orden cronológico, según sus fechas de publicación.

\section{Albatross Press}

Albatross Press, más específicamente la Albatross Modern Continental Library, fue fundada por John Holroyd-Reece, Max Christian Wegner y Kurt Enoch en Alemania en 1932. Normalmente son considerados como los primeros libros modernos en rústica producidos en masa. Por consiguiente, tienen un gran impacto e influencia en la producción editorial de otras imprentas, tanto europeas como globales, durante el siglo XX. En particular se suelen atribuir muchos aspectos del diseño del libro de bolsillo moderno a los libros producidos por Albatross. Por ejemplo, "their size, $181 \times 112 \mathrm{~mm}$, [was the] 'golden ratio' of 1.618 widely used in art and architecture. The same size then became the standard of British paperbacks after Penguin Books adopted it". ${ }^{25}$ Obviamente, los Breviarios pueden incluirse en esta trayectoria y tradición estética por el tamaño similar de sus libros (170 x 105 mm), que también reflejan una divina proporción.

En cuanto a su presentación física, los libros que produjo Albatross Press dentro de su Modern Continental Library "were packaged to please, with captivating covers in kelly green, acid yellow, robin's egg blue, red, and magenta, each color for a different genre. Even by today's standards, Albatross's streamli-

\footnotetext{
${ }^{24}$ Otras colecciones globales que podrían ser incluidas como modelos para los Breviarios son Everyman's Library, la Colección Horizonte de la Editorial Sudamericana, la Biblioteca Contemporánea de la Editorial Losada y la Colección Austral de Espasa-Calpe. Sin embargo, ninguna utiliza un sistema organizacional con colores, a excepción de la Austral, ni tenían un diseño parecido a los Breviarios. Algunos críticos han señalado la conexión entre estos y la Biblioteca del Autodidacto de la Editorial Claridad, pero no creo que tenga tantos vínculos estéticos con los Breviarios como los que comparten con las otras colecciones estudiadas aquí.

${ }^{25}$ Lise Jaillant, Cheap Modernism: Expanding Markets, Publishers' Series and the AvantGarde (Edimburgo: Edinburgh University Press, 2017), 108.
} 
ned covers convey a forward-looking elegance". ${ }^{26}$ Aunque hay algunas coincidencias en los colores usados por la Modern Continental Library y los Breviarios, los temas incluidos en cada serie se bifurcan.

\begin{tabular}{|l|l|}
\hline Tema/Sujeto & Color \\
\hline Cuentos y obras cómicas & Anaranjado \\
\hline Viaje & Verde \\
\hline Aventura y crimen & Rojo \\
\hline Novelas psicológicas & Amarillo \\
\hline Romances (literatura amorosa) & Azul \\
\hline Biografía e historia & Magenta \\
\hline
\end{tabular}

Tabla 1. La división temática de los libros de Albatross Press.

Esas diferencias en tema y género probablemente tienen que ver con el hecho de que la colección de Albatross Press se concentra en la literatura exclusivamente, mientras que la del FCE tiene un enfoque más bien académico y, por eso, la mayoría de los títulos son ensayos críticos sobre un tema o tipo de literatura. En cualquier caso, la decisión de implementar un sistema organizacional marcado por sus colores distinguió a Albatross Press de la mayoría de sus competidores y lo puso en el mapa global del mercado editorial. Además, este sistema visual ayuda a cualquier lector a encontrar un título que le guste: "Albatross chose different colours to indicate the type of books, wrote The Times, in order to 'save the English reader trouble at a railway or other bookstall, but also to help the foreign bookseller and reader, who will thus be able to tell at a glance the nature of each volume'". ${ }^{27}$ Más aún, los editores decidieron incluir las descripciones de las obras -junto con la explicación del sistema de colores y los precios- en tres idiomas (inglés, francés y alemán) para facilitar la selección de un título.

\footnotetext{
${ }^{26}$ Michele K. Troy, Strange Bird: The Albatross Press and the Third Reich (New Haven, CT: Yale University Press, 2017), 5.

27 Jaillant, Cheap Modernism, 109.
} 


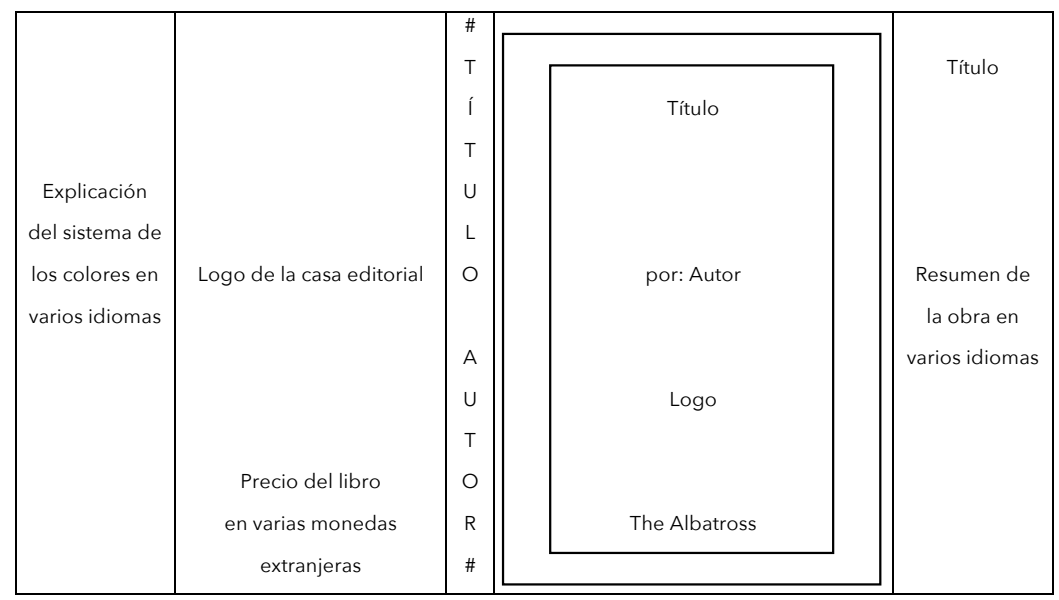

Imagen 5. Esquema general de las cubiertas de Albatross Books.

Otro aspecto de los libros de la Albatross Modern Continental Library que quiero señalar es el nivel de detalle que presentan los colofones de cada ejemplar. Casi un presagio de lo que veremos en los Breviarios del FCE, los colofones de esta colección del Albatross Press indican no sólo la imprenta, sino también las fuentes tipográficas usadas a lo largo del libro y el fabricante del papel. Por eso, según Lise Jaillant, "the colophon thus positioned Albatross books in the tradition of the beautiful book... In short, Albatross positioned itself as a luxury brand priced for a broad audience". ${ }^{28}$ Este interés en revelar cómo se producen los elementos físicos de cada libro, y también un deseo de indicar las personas que fueron responsables por tal producción, fue algo nuevo en el mundo del libro producido en masa. Dicho de otra manera, este interés en producir no solamente libros baratos y accesibles, sino también bien hechos, refleja una estrategia editorial innovadora por parte de Albatross Press que, hasta cierto punto, continúa con los Breviarios. El último elemento notable de la presentación física de la colección de Albatross Press es su creación y el uso constante de un logo distintivo que "served to strengthen brand recognition". ${ }^{29}$ Aunque los Breviarios no llevaron un logo único que reflejara el propósito de la serie en sí, el logo del FCE aparece en la portada, y a veces en las cubiertas de tapa dura, de cada libro en la colección.

\footnotetext{
28 Ibid., 108-109.

29 Ibid., 109.
} 


\section{Penguin Books}

Allen Lane y sus hermanos, Richard y John, fundaron la empresa de Penguin Books en Inglaterra en 1935 con la publicación de Ariel de André Maurois. ${ }^{30}$ Similar al propósito de Holroyd-Reece, Wegner y Enoch con la Modern Continental Library de Albatross Press, los Lane querían producir libros baratos y bien diseñados, para un público general. En la actualidad los libros de Penguin son unos de los más identificables en el mercado, por su estilo único. Dicho eso, "this 'classic' look, the one everyone knows, was not entirely new: it derived to a degree from the Albatross series of 1932. These featured simple typography designed by Hans Mardersteig, colour coding, an easily memorable bird's name and a recognizable drawing of it used as the logo". ${ }^{31}$ En su estudio de la casa editorial, Stuart Kells explica la razón de estas coincidencias de diseño entre los libros de Penguin Books y Albatross Press:

In 1933 Holroyd-Reece met Allen to discuss the possibility of an AlbatrossBodley partnership in which the firms would issue paperbound books in a common format and share printing costs. Powerful forces prevented this tie-up: problems with copyright; the rise of Nazism in Germany; and, inherited from his uncle, Allen's allergy to partnerships. But Allen gave an Albatross book, and one from its sister firm Tauchnitz, to Stan Olney, The Bodley Head's trade manager, and asked him to work... on a costing for the reprint series at the Woolworths-Shaw price-point of sixpence... The brothers would create a new Albatross. A British Albatross. A Lane Albatross. ${ }^{32}$

Así que los libros producidos por Penguin Books tomaron inspiración directa de los de la colección de la Modern Continental Library de Albatross Press. Además de estos elementos de su diseño estético, los libros de Penguin también tomaron prestado el tamaño ideal de los libros de aquellos (181 x 112 mm). Sin embargo, la codificación por colores de sus títulos es diferente.

\footnotetext{
${ }^{30}$ Los primeros títulos de Penguin Books se produjeron bajo el sello de The Bodley Head. En 1936 Penguin Books se estableció como una firma editorial separada.

${ }^{31}$ Phil Baines, Penguin by Design. A Cover Story, 1935-2005 (Nueva York: Penguin, 2005), 13-14.

${ }^{32}$ Stuart Kells, Penguin and the Lane Brothers. The Untold Story of a Publishing Revolution (Victoria, Australia: Black Inc., 2015), 121-122.
} 


\begin{tabular}{|l|l|}
\hline Tema/Sujeto & Color \\
\hline Drama & Rojo \\
\hline Ficción & Anaranjado \\
\hline Misceláneo & Amarillo \\
\hline Crimen & Verde \\
\hline Autobiografías & Azul oscuro \\
\hline Ensayos & Púrpura \\
\hline Viaje y aventura & Rojo oscuro \\
\hline Noticias globales & Gris \\
\hline
\end{tabular}

Tabla 2. La división temática de los libros de Penguin.

Aunque la mayoría de las ideas que inspiró la producción de los libros de Penguin Books fue tomada de Albatross Press, hay algunos aspectos novedosos en los libros de Penguin. En particular, hay que mencionar la división horizontal de cada una de sus tapas en tres secciones uniformes. ${ }^{33}$

Esta división tripartita de las portadas de los Penguin Books es todavía su aspecto más icónico y lo que distingue un libro suyo de cualquier otro producido en masa durante el siglo XX. Si bien quería enfocarme sobre todo en la serie original de los Penguin, también hay que destacar la segunda colección publicada por Allen Lane bajo el mismo sello de Penguin Books: Ios Pelican, centrados en obras serias de no ficción. Más específicamente, los títulos dentro de la serie Pelican, que aparecieron por primera vez en mayo de 1937, siempre caían dentro de una de las siguientes categorías temáticas: ciencia, astronomía, historia, política, economía o arqueología. Aunque suele citarse los libros de Penguin como el gran éxito de Lane y sus hermanos, los Pelican también fueron muy exitosos. Según Lane, "[t]he really amazing thing, the extraordinary eye-opener that surprised the most optimistic of us, was the immediate and overwhelming success of the Pelicans. Who would have imagined that, even at $6 \mathrm{~d}$, there was a thirsty public anxious to buy thousands of copies of books on science, sociology, economics, archaeology, astronomy and other equally serious subjects?". ${ }^{34}$

\footnotetext{
${ }^{33}$ Sin duda alguna este diseño inspiró no sólo al nombre de la Colección Horizonte de la Editorial Sudamericana, sino también las portadas de los libros en esta serie.

34 Paul Laity, "Pelican Books Take Flight Again", The Guardian (25 de abril de 2014).
} 


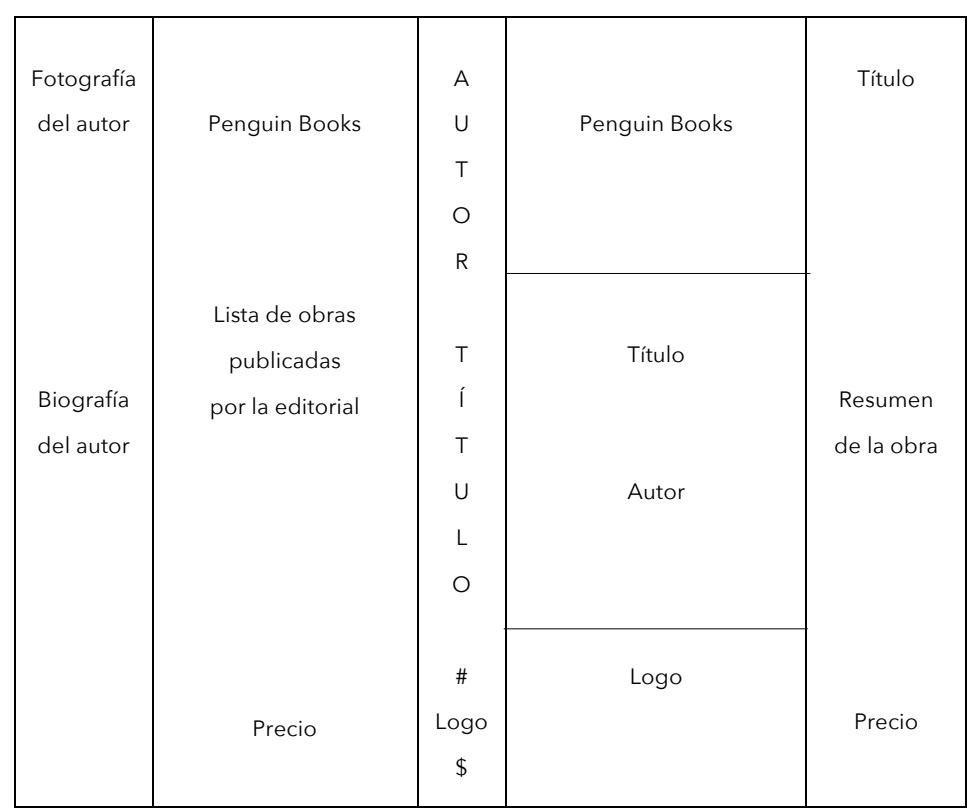

Imagen 6. Esquema general de las cubiertas de Penguin Books.

En cierto sentido, es necesario tener estas dos series en mente para evaluar lo que viene después con los Breviarios. Dicho de otra manera, los Breviarios son como una combinación -o un híbrido- de estas dos colecciones de la editorial británica. Por un lado, se nota la inspiración estética de los libros de Penguin en el diseño de cada tomo de los Breviarios, por otro, está la influencia del propósito intelectual de los Pelican, que aspiraron a ser "the vehicle for serious, non-fiction works for the 'intelligent layman'". ${ }^{35}$

${ }^{35}$ Chris Browne, "A Brief History of Pelican Books", acceso el 27 de enero de 2020, http:// penguinsandothers.blogspot.com/p/blog-page.html. 


\section{Biblioteca Emecé de Obras Universales}

La última colección que quiero analizar como precursora de los Breviarios es la Biblioteca Emecé de Obras Universales. A diferencia de Albatross Press, o aun Penguin Books, que suele asociarse con una serie sobresaliente -tanto por su diseño como por su contenido- Emecé Editores fue, y todavía es, una editorial enorme con una multitud de colecciones exitosas y memorables. ${ }^{36}$ Desde su Colección Buen Aire y sus Cuadernos de Grandes Ensayistas hasta su serie Séptimo Círculo, dirigida por Jorge Luis Borges y Adolfo Bioy Casares, Emecé se considera uno de los líderes en el mundo editorial latinoamericano.

Fundado en 1939 por Mariano Medina del Río, Álvaro de las Casas y Carlos Braun Menéndez, Emecé inicialmente se enfocó en la publicación de obras gallegas, pero después del fracaso al no poder vender muchos libros, empezó a especializarse en obras canónicas españolas en términos más generales y, poco a poco, incorporó varias obras latinoamericanas a sus catálogos. A pesar de que Emecé produjo muchas colecciones distintas e importantes durante la primera década de su existencia, solamente me detendré en la Biblioteca Emecé por las similitudes que presenta con los Breviarios.

En línea con las tendencias estéticas vistas hasta ahora en otras editoriales internacionales, los volúmenes de la Biblioteca Emecé tenían un tamaño parecido (18 x $11.5 \mathrm{~mm}$ ) y aparecieron "encuadernados en tela, con sobrecubierta en dos colores". ${ }^{37}$ La introducción a la colección en el Catálogo general perpetuo de Emecé subraya la importancia tanto de los aspectos físicos ("calidad de papel, legibilidad de la impresión, encuadernación agradable y resistente") como de los intelectuales ("textos íntegros y bien corregidos, traducciones fieles a la letra y al espíritu, notas informativas o aclaratorias, índices onomásticos o analíticos cuando la índole del libro así lo requiera") de esta biblioteca universal. ${ }^{38}$ Siguiendo la tradición que empezó Albatross Press con su Modern Continental Library, los libros de la Biblioteca Emecé estaban codificados por color según su tema. Sin embargo, esta colección consta de más secciones temáticas que las otras series.

${ }^{36}$ Desde 2001 Emecé Editores forma parte del conglomerado editorial de Grupo Planeta.

${ }^{37}$ Catálogo general perpetuo ([Argentina]: Emecé Editores, n. d.).

$38 \mathrm{lbid}$. 


\begin{tabular}{|l|l|}
\hline \multicolumn{1}{|c|}{ Tema/Sujeto } & Color \\
\hline $\begin{array}{l}\text { Biografía y memorias, } \\
\text { literatura epistolar y oratoria }\end{array}$ & Amarillo \\
\hline Ciencias & Verde olivo \\
\hline Poesía & Marrón-gris \\
\hline Ensayo y crítica & Anaranjado \\
\hline Ficción (novela y cuento) & Rosado \\
\hline Filosofía y religión & Verde azulado \\
\hline Clásicos castellanos & Verde gris \\
\hline Clásicos griegos y latinos & Azul \\
\hline Viajes y exploración & Marrón \\
\hline Historia y arqueología & Mostaza \\
\hline Referencia y varios & Gris \\
\hline
\end{tabular}

Tabla 3. La división temática de los libros de la Biblioteca Emecé de Obras Universales.

Aunque existe una gran variedad de temas discutidos a lo largo de la colección en sí, la mayor parte de la biblioteca se relaciona con "los clásicos de la literatura universal, antigua y moderna, y las obras maestras de historia o de crítica en los diversos órdenes del conocimiento". 39

Junto con ese interés en los aspectos visuales de cada tomo en la Biblioteca Emecé, los editores hacían hincapié en la accesibilidad de los libros:

No cabe duda, por tanto, que si la base intelectual de la cultura es el libro, la constitución de una biblioteca, por modesta que sea, en todos los hogares dignos de tal nombre es una necesidad fundamental, una exigencia imperativa de la vida espiritual... Contribuir a esta empresa social, hacer asequible al mayor número posible la formación de esa biblioteca familiar, es el propósito cardinal de esta colección. ${ }^{40}$

\footnotetext{
$39 \mathrm{lbid}$

${ }^{40} \mathrm{lbid}$.
} 


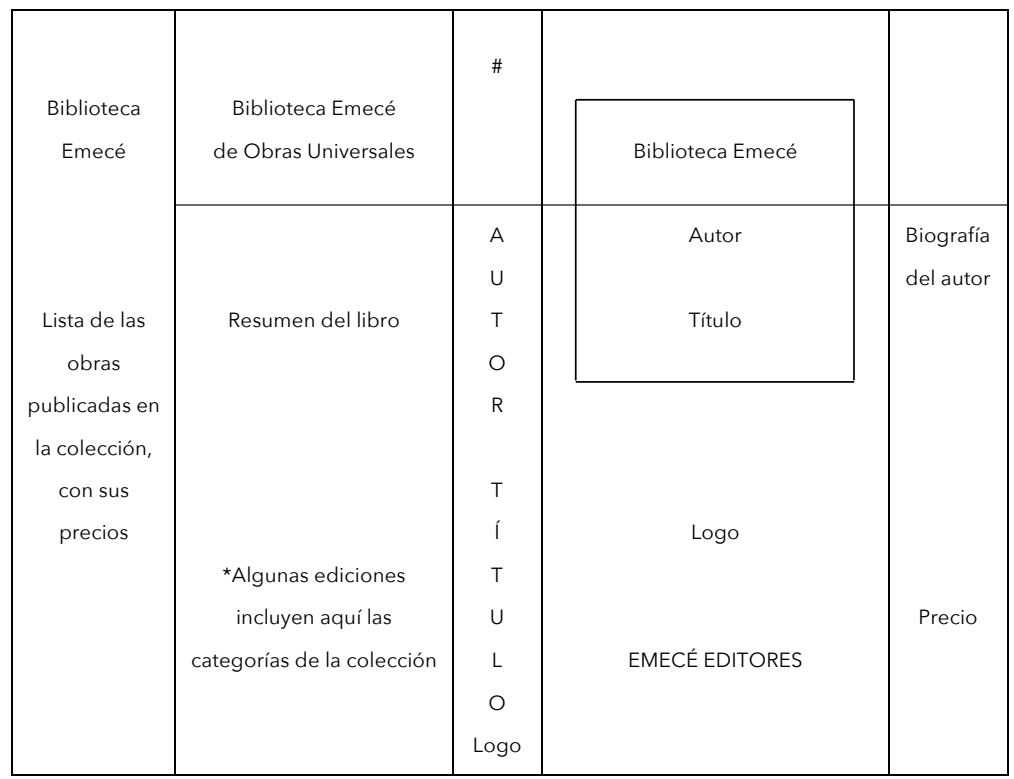

Imagen 7. Esquema general de las cubiertas de la Biblioteca Emecé.

También se nota el énfasis de poner los libros dentro de esta biblioteca al alcance de todos, por la variedad de opciones de compra. Particularmente, su publicidad señala el hecho de que "esta colección puede adquirirse, en su total o por secciones, en cómodas cuotas mensuales", y el precio de cada tomo se basa en su extensión. ${ }^{41}$

Por lo general, las características compartidas entre los Breviarios y todas las diferentes colecciones discutidas revelan la importancia de la mercadotecnia y la creación de una marca asociada con cierto tipo de producto de calidad. Dicho de otra manera, la decisión del FCE de utilizar una estética bien conocida, una estrategia muy exitosa no sólo en Europa, sino también alrededor del mundo, demuestra su conocimiento de las tendencias internacionales en el campo editorial, que pudo adaptar y desarrollar para sus propios lectores y mercados latinoamericanos.

${ }^{41} \mathrm{lbid}$. Los tomos de hasta 240 páginas costaban $\$ 3,50 \mathrm{~m} / \mathrm{arg}$; los de 241 hasta 464 páginas $\$ 4,50 \mathrm{~m} / \mathrm{arg}$., y los de 465 hasta 672 páginas $\$ 5,50 \mathrm{~m} / \mathrm{arg}$. Si un tomo contiene un gran número de imágenes u otro material gráfico, o si existen restricciones de copyright, hay un precio especial que no se puede precisar en términos generales. 


\section{El contenido}

Además de los aspectos físicos sobresalientes de los Breviarios hay que destacar el contenido de los libros en sí. De acuerdo con la descripción de la colección que aparece en la sobrecubierta de cada tomo durante su primera etapa (1948-1965), fueron "redactados por especialistas de crédito universal, [y] cada uno de estos Breviarios es un tratado sumario y completo sobre la materia que anuncia su título". Por tanto, se espera encontrar no sólo los nombres de muchos autores e intelectuales notables en la cubierta de cada libro, sino también un texto bien investigado y escrito dentro de sus páginas.

En cuanto a los autores, o sea los "especialistas de crédito universal", hay varios muy conocidos en la actualidad, que seguramente habrían sido distinguidos por lectores latinoamericanos a mediados del siglo XX. Por ejemplo, pensando solamente en un público latinoamericano, es probable que los lectores de la serie reconocieran a ciertos intelectuales hispanohablantes cuyos nombres ya aparecieron en libros, revistas y aun en periódicos de la época como Alfonso Reyes, Jorge Luis Borges y Enrique Anderson Imbert, entre otros. Aparte de estos escritores latinoamericanos, es difícil saber si cualquier lector de los Breviarios reconocería la fama o reputación de los expertos de otros países. Aunque ciertos intelectuales, como Aaron Copland o Bertrand Russell, fueron muy destacados a lo largo del siglo XX por sus éxitos y premios internacionales, hay otros que quizá no fueron muy conocidos por el público en general. ${ }^{42}$ Sin embargo, me imagino que quienes compraron títulos de los Breviarios confiaban en que los editores y directores de la serie seleccionaban a los expertos con mucho cuidado. ${ }^{43}$ Además de la importancia del impacto del reconocimiento o la fama internacional de ciertos autores para el éxito de los Breviarios, está la importancia de la selección de los textos en sí. Por eso, en esta segunda parte de mi análisis quiero enfocarme, más que nada, en lo que considero cierto tipo de reciclaje textual. En primer lugar, examinaré el gran número de títulos de los Breviarios que son traducciones de otros libros de Europa o los Estados Unidos. Más específicamente, muchos de los libros en la serie del FCE forman parte de otras colecciones globales que son parecidas o,

\footnotetext{
${ }_{42}$ Aaron Copland, Cómo escuchar la música (Breviarios 101); Bertrand Russell, Autoridad e individuo (Breviarios 15); Bertrand Russell, Religión y ciencia (Breviarios 55).

${ }^{43}$ Aunque no he podido consultar los archivos del FCE para verificar cómo los directores seleccionaron a los colaboradores, la manera en que se presentaron los libros de la colección, en términos de su formato y contenido, no requiere la consulta de tal archivo, sino un análisis bibliográfico de los libros en sí.
} 
por lo menos, tienen el mismo objetivo del acceso universal. En segundo lugar, recurriré a los textos originales de los Breviarios para mostrar ciertos aspectos del reciclaje textual (y visual) en su presentación. ${ }^{44}$

Durante la primera etapa de existencia de los Breviarios (1948-1965) se publicaron 186 libros distintos. ${ }^{45}$ De manera interesante, la mayoría de esos títulos ya había sido publicada por otras editoriales internacionales. En términos específicos, de esos 186 libros, 152 se publicaron primero en inglés, alemán o francés con editoriales en los Estados Unidos o Europa (81.6\%). Luego, el FCE compró los derechos para traducir estos títulos al español y publicarlos. Por tanto, solamente se publicaron 34 textos originales (18.3\%) durante esta primera época de los Breviarios. ${ }^{46}$

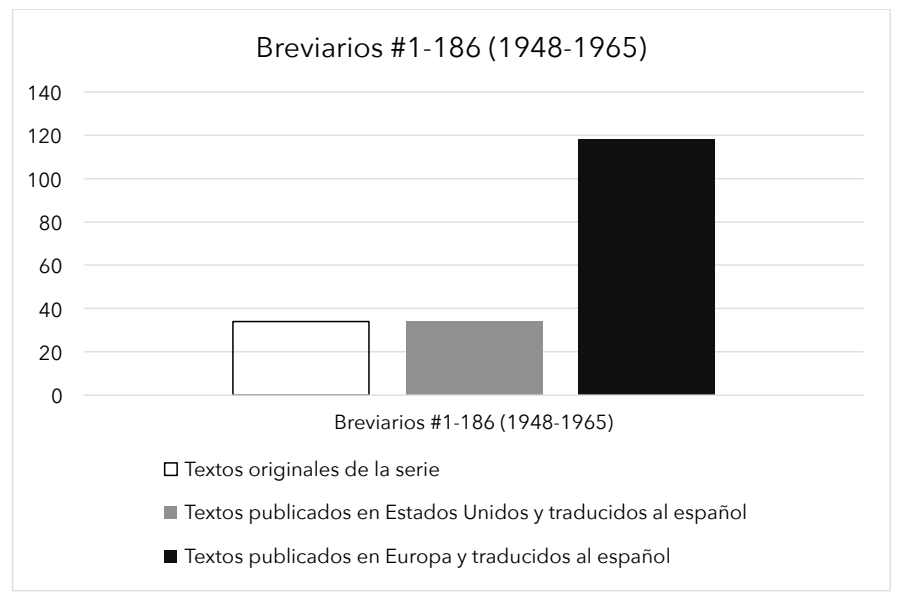

${ }^{44}$ Entiendo por "texto original" un libro en esta colección que no había sido publicado por otra casa editorial.

${ }^{45}$ Este número se refiere a las primeras ediciones de los Breviarios. Aunque varios ejemplares pasaron por ediciones, o aun reimpresiones, múltiples durante este periodo, sólo quiero concentrarme en el número absoluto de títulos, no en el número total de libros producidos.

${ }^{46}$ Dependiendo del año específico, hay una variación de los títulos originales del FCE $y$, por tanto, una variedad de porcentajes. Dicho eso, el mayor número de títulos originales producido durante los años en cuestión es cinco en el año 1952, lo cual equivale a 31\% de todos los libros producidos para la colección de los Breviarios en ese año (había 16 libros producidos en total en el año 1952). Así que, si bien hay algunos años en este rango con un porcentaje más alto del promedio, el número de títulos originales producidos cada año siempre es mucho más bajo que el número de libros traducidos de otros lenguajes para la serie. 




Otro aspecto llamativo de los libros traducidos al español para esta colección mexicana es el hecho de que, en algunos casos, los títulos seleccionados de otras editoriales vienen de bibliotecas -o series- que tienen ciertos objetivos similares a los de los Breviarios. Por ejemplo, varios títulos ingleses vienen de la Home University Library of Modern Knowledge (4.8\%), la Hutchinson University Library (4.3\%) o incluso de la serie Pelican de Penguin Books (2.6\%).47 Similar a lo que vemos con otras colecciones, la Home University Library of Modern Knowledge (1911-1970) se caracteriza por ser "pioneer in supplying serious literature for a large section of the public who are interested in the liberal education of the State".48 Más aún, cada tomo dentro de esta serie fue escrito especialmente para la serie por "a recognised authority". ${ }^{49}$ Del mismo modo, la Hutchinson University Library (1947-1998) publicó "relatively succinct overviews of a specialized field in the natural sciences, social sciences, or humanities".50 Aunque la mayoría de los libros que el FCE publicó en los Breviarios

\footnotetext{
${ }^{47}$ De manera sorprendente, de los cuatro primeros títulos publicados en la colección (1948), tres son de la Home University Library of Modern Knowledge (75\%).

${ }^{48}$ Esta descripción de la colección viene de la cubierta de The English Language, de Logan Pearsall Smith (1928), y se reproduce en el proyecto digital de John Krygier, "A Series of Series. 20th-Century Publishers Book Series", acceso el 27 de enero de 2020, https://serie sofseries.owu.edu/home-university-library/.

${ }^{49}$ John Krygier "A Series of Series..."

50 lbid.
} 
no formó parte de las otras colecciones o series analizadas, algunos sí vienen de estas colecciones, por ejemplo, un manojo proviene de Pelican (cinco del número total), lo cual demuestra la importancia de sus precursores no sólo por sus aspectos estéticos, sino también por su contenido.

Junto con los libros traducidos de otros idiomas pertenecientes a otras colecciones alrededor del mundo, también hay ciertos textos de los Breviarios que aparecieron -en parte- por primera vez en algunos periódicos o revistas literarias. Por ejemplo, la revista Sur de Victoria Ocampo, una de las revistas literarias más importantes en América Latina durante el siglo XX, publicó algunos ensayos y artículos que parecen ser los precursores textuales para algunos títulos de los Breviarios. Por ejemplo, "Rumbo a Goethe", un ensayo de Alfonso Reyes, se publicó en el número cinco de Sur (1932). Este artículo parece ser un bosquejo inicial para el libro de Reyes sobre el autor alemán, Trayectoria de Goethe, que salió como parte de la colección de los Breviarios en 1954. De manera similar, un artículo titulado "El 'Dasein' Heideggeriano en la generación de 98", escrito por Segundo Serrano Poncela, apareció en Sur en 1950 y tres años más tarde salió, con el sello del FCE, El pensamiento de Unamuno, del mismo autor, cuyo contenido se relaciona con el tema de su artículo publicado anteriormente. Otro ejemplo es el libro Lautréamont de Gaston Bachelard. A pesar de que este libro no salió dentro de la serie de los Breviarios sino hasta 1985, todavía puede incluirse como ejemplo del fenómeno del reciclaje textual porque Bachelard escribió un artículo sobre Lautréamont que apareció en Sur (1940). Aunque estos ejemplos solamente vienen de una revista literaria de América Latina de la época, subrayan la idea de que incluso textos originales publicados en la colección Breviarios resultan ser reciclados de otras publicaciones.

El último tipo de reciclaje material que puede identificarse en los libros de esta colección del FCE es visual. Dicho de otro modo, algunas imágenes que aparecen en los Breviarios ya habían aparecido en otros libros publicados. En el Manual de zoología fantástica (1957) de Jorge Luis Borges y Margarita Guerrero hay una serie de dibujos que ilustran cómo son varias criaturas inventadas del mundo de la ficción. Aunque algunas son bien conocidas, como el unicornio, el minotauro o aun el uróboros, hay otras que son originales del libro en sí. Por tanto, la inclusión de estas imágenes parecería una buena idea para ayudar al lector a entender mejor la composición física de esas criaturas únicas. Sin embargo, casi la mitad de los dibujos fueron tomados directamente de otro libro escrito por Borges anteriormente, con la ayuda de Adolfo Bioy Casares, y no tienen nada que ver con los textos del Manual de zoología fantástica que 
describen esas criaturas inventadas. Estos dibujos tampoco se relacionan con el texto original de Un modelo para la muerte (1946), donde se publicaron por primera vez. En cualquier caso, el reciclaje -tanto de textos como de imágenes o dibujos- en los Breviarios justifica la importancia de analizar sus precursores estéticos y textuales. ${ }^{51}$

\section{Conclusiones}

Sin lugar a dudas, la creación y publicación de los Breviarios tuvo gran impacto en la fama internacional del Fondo de Cultura Económica. En particular, esta serie influyó en la producción en masa y la accesibilidad al conocimiento universal no sólo en México, sino también en América Latina. Por lo general, la disponibilidad de unos libros como los Breviarios posibilita el crecimiento de un público más autodidacta a un costo relativamente bajo. Dicho de otra manera, los libros -especialmente los producidos en masa- ocupan un lugar crucial en el desarrollo de cualquier sociedad.

Según Thomas Carlyle, "of all the things which man can do or make here below, by far the most momentous, wonderful and worthy are the things we call Books! [...] The thing we call 'bits of paper with traces of black ink,' is the purest embodiment a Thought of man can have. No wonder it is, in all ways, the activest and noblest". ${ }^{2}$ De hecho, para Carlyle no es necesario asistir a una escuela especializada o aun a la universidad si hay libros -y si el individuo ya sabe leer-, porque los libros en sí forman la universidad verdadera: "the place where we are to get knowledge, even theoretic knowledge, is the Books themselves! It depends on what we read, after all manner of Professors have done their best for us. The true University of these days is a collection of Books".53

Esto es precisamente lo que hizo el Fondo de Cultura Económica con los Breviarios: "[llevaron] la universidad al hogar". ${ }^{44}$ Sin embargo, este concepto de "llevar la universidad al hogar" tampoco es una idea totalmente nueva en el

\footnotetext{
${ }^{51}$ Hasta cierto punto se puede explicar la preponderancia del reciclaje textual (y visual) de fuentes argentinas -especialmente la presencia de Jorge Luis Borges-, debido a las redes de contacto del director de los Breviarios y del FCE, Orfila Reynal.

52 Thomas Carlyle, On Heroes, Hero-Worship, \& The Heroic in History. Six Lectures Reported with Emendations and Additions (Nueva York: D. Appleton \& Co., 1842), 11-12.

${ }^{53} \mathrm{Ibid}$., 186. Estos dos pasajes vienen de su lectura "The Hero as Man of Letters", en la cual defiende el papel de los intelectuales y su producción escrita.

${ }^{54}$ La sobrecubierta de cada tomo de los Breviarios que se publicó durante la primera etapa de la serie describe así la misión de la colección.
} 
mundo editorial y, como hemos visto, tiene sus raíces en el trabajo fundacional de otras editoriales internacionales. Por eso, hay que destacar los aspectos sobresalientes de ciertas colecciones reconocidas de empresas como Albatross Press, Penguin Books y Emecé Editores, debido a su influencia en la presentación y la mercadotecnia de los Breviarios y, por consiguiente, su éxito.

\section{Referencias}

Alfonso Reyes-Arnaldo Orfila Reynal. Correspondencia (1923-1957). Edición de Serge I. Zaïtzeff. Buenos Aires: Siglo Veintiuno, 2009.

Álvarez, Gonzalo, Alejandro Archain y Carlos Díaz. Un editor de tres siglos. La vida y los libros de Arnaldo Orfila Reynal. Buenos Aires: Eudeba, 2015.

Bachelard, Gaston. "Lautréamont: Poeta de los músculos y del grito". Sur 73 (1940): 60-68.

Bachelard, Gaston. Lautréamont. México: Fondo de Cultura Económica, 1985.

Baines, Phil. Penguin by Design. A Cover Story, 1935-2005. Nueva York: Penguin, 2005.

Bioy Casares, Adolfo y Jorge Luis Borges. Un modelo para la muerte. Buenos Aires: Editorial Oportet y Haereses, 1946.

Borges, Jorge Luis y Delia Ingenieros. Antiguas literaturas germánicas. México: Fondo de Cultura Económica, 1951.

Borges, Jorge Luis y Margarita Guerrero. Manual de zoología fantástica. México: Fondo de Cultura Económica, 1957.

Bowra, C. M. Historia de la literatura griega. México: Fondo de Cultura Económica, 1948.

Browne, Chris. "A Brief History of Pelican Books". Acceso el 27 de enero de 2020. http://penguinsandothers.blogspot.com/p/blog-page.html.

Candioti, Alberto M. "Hay gran demanda de libros argentinos en México". Gaceta del Libro 3 (1945): 27-28.

Carlyle, Thomas. On Heroes, Hero-Worship, \& the Heroic in History. Six Lectures Reported with Emendations and Additions. Nueva York: D. Appleton \& Co., 1842.

Catálogo general perpetuo. [Argentina]: Emecé Editores, n. d.

Copland, Aaron. Cómo escuchar la música. México: Fondo de Cultura Económica, 1954.

Cosío Villegas, Daniel. Memorias. México: Consejo Nacional de Fomento Educativo, 1986. 
Díaz Arciniega, Víctor. Historia de la Casa. Fondo de Cultura Económica (19341994). México: Fondo de Cultura Económica, 1994.

Diego, José Luis de. "Actualidad del mercado del libro: el caso argentino". Revista Hispánica Moderna 71.2 (2018): 131-150.

Diego, José Luis de. Editores y políticas editoriales en Argentina, 1880-2000. México: Fondo de Cultura Económica, 2006.

Fell, Claude. José Vasconcelos: los años del águila (1920-1925). Educación, cultura e iberoamericanismo en el México posrevolucionario. México: Universidad Nacional Autónoma de México, 1989.

Fondo de Cultura Económica. Libro conmemorativo del 45 aniversario. México: Fondo de Cultura Económica, 1980.

Fondo de Cultura Económica. Libro conmemorativo del primer medio siglo del Fondo de Cultura Económica. México: Fondo de Cultura Económica, 1984.

Garciadiego, Javier. El Fondo, La Casa y la introducción del pensamiento moderno. México: Fondo de Cultura Económica, 2016.

Garone Gravier, Marina. Historia en cubierta: El Fondo de Cultura Económica a través de sus portadas (1934-2009). México: Fondo de Cultura Económica, 2011.

González de la Vara, Armida y Álvaro Matute, editores. El exilio español y el mundo de los libros. Guadalajara: Universidad de Guadalajara, 2002.

Granados Salinas, Tomás. Libros. México: Secretaría de Cultura, 2017.

Jaillant, Lise. Cheap Modernism: Expanding Markets, Publishers' Series and the Avant-Garde. Edimburgo: Edinburgh University Press, 2017.

Kells, Stuart. Penguin and the Lane Brothers. The Untold Story of a Publishing Revolution. Victoria, Australia: Black, Inc., 2015.

Krauze, Enrique. Daniel Cosío Villegas. Una biografía intelectual. Barcelona: Tusquets, 2007.

Krygier, John. "A Series of Series. 20th Century Publishers Book Series". Acceso el 27 de enero de 2020. https://seriesofseries.owu.edu/.

Laguardia Martínez, Jacqueline. "La industria editorial cubana: evolución y desarrollo". En Memorias 22. Feria Internacional del Libro de la Habana. 160-197. La Habana: Editorial Científico-Técnica, 2012.

Laity, Paul. "Pelican Books Take Flight Again". The Guardian (25 de abril de 2014). Lewis, Jeremy. Penguin Special. The Life and Times of Allen Lane. New York: Penguin, 2005.

López Brun, María Eugenia, editora. Arnaldo Orfila Reynal. La pasión por los libros. Edición homenaje. Guadalajara: Universidad de Guadalajara, 1993. 
McKenzie, Donald Francis. Bibliography and the Sociology of Texts. Cambridge, MA: Cambridge University Press, 1999.

McKenzie, Donald Francis. Making Meaning: "Printers of the Mind" and Other Essays. Edición de Peter D. McDonald y Michael F. Suarez. Amherst, MA: University of Massachusetts Press, 2002.

Nicolson, Harold. La diplomacia. México: Fondo de Cultura Económica, 1948.

Nova Ramírez, Víctor Erwin. "Arnaldo Orfila Reynal. El editor que marcó los cánones de la edición latinoamericana". Tesis de maestría. Universidad Autónoma Metropolitana, 2013.

Ochoa Sandy, Gerardo. 80 años: Las batallas culturales del Fondo. México: Nieve de Chamoy, 2014.

Orfila Reynal, Arnaldo. "Orígenes y misión de 'Fondo de Cultura Económica'". Gaceta del Libro 3 (1945): 25-26.

Reyes, Alfonso. "Rumbo a Goethe". Sur 5 (1932): 7-86.

Reyes, Alfonso. Trayectoria de Goethe. México: Fondo de Cultura Económica, 1954.

Rivera, Jorge B. "El auge de la industria cultural (1930-1955)". En El escritor y la industria cultural, 94-127. Buenos Aires: Centro Editor de América Latina, 1981.

Rivera, Jorge B. La forja del escritor profesional (1900-1930). Los escritores y los nuevos medios masivos. Buenos Aires: Centro Editor de América Latina, 1967.

Rosales Morales, Francisco Javier. "Un acercamiento a los lectores de las publicaciones de la Secretaría de Educación Pública". Revista Mexicana de Historia de la Educación 4.8 (2016): 175-199.

Russell, Bertrand. Autoridad e individuo. México: Fondo de Cultura Económica, 1949.

Russell, Bertrand. Religión y ciencia. México: Fondo de Cultura Económica, 1951.

Serrano Poncela, Segundo. "El 'Dasein' Heideggeriano en la generación de 98". Sur 184 (1950): 35-57.

Serrano Poncela, Segundo. El pensamiento de Unamuno. México: Fondo de Cultura Económica, 1953.

Sorá, Gustavo. Editar desde la izquierda en América Latina. La agitada historia del Fondo de Cultura Económica y de Siglo XXI. Buenos Aires: Siglo Veintiuno, 2017.

Sorá, Gustavo. "El libro y la edición en Argentina. Libros para todos y modelo hispanoamericano". Políticas de la Memoria 11 (2011): 125-145. 
Tanselle, G. Thomas. Bibliographical Analysis. A Historical Introduction. Cambridge, MA: Cambridge University Press, 2009.

Tanselle, G. Thomas. Literature and Artifacts. Charlottesville, VA: Bibliographical Society of the University of Virginia, 1998.

Troy, Michele K. Strange Bird: The Albatross Press and the Third Reich. New Haven, CT: Yale University Press, 2017.

Turberville, Arthur Stanley. La Inquisición española. México: Fondo de Cultura Económica, 1948. 